Revista Agri-Environmental Sciences, v. 7, Ed. Especial, e021002, 2021

DOI: https://doi.org/10.36725/agries.v7i2.5294

https://revista.unitins.br/index.php/agri-environmental-sciences/index

Arroz.do

Tocantins

O CORACẼO DO BRASIL

Arroz do Tocantins: no coração do Brasil

\title{
MANEJO DA IRRIGAÇÃO NA CULTURA DO ARROZ IRRIGADO E NA EFICIÊNCIA DO USO DA ÁGUA EM VÁRZEAS TROPICAIS
}

\author{
Alberto Baêta dos Santos ${ }^{1}$; Alexandre Bryan Heinemann² ${ }^{2}$ Mellissa Ananias Soler da Silva ${ }^{3}$; Luís \\ Fernando Stone ${ }^{4}$, Leandro Barbosa Pimenta ${ }^{5}$ Deivison Santos ${ }^{6}$
}

\section{RESUMO:}

O manejo apropriado da água de irrigação está entre as técnicas necessárias para atingir não apenas alto potencial produtivo como também maior eficiência no uso de água e insumos nos sistemas agrícolas irrigados. Objetivou-se com este estudo determinar a influência do manejo da irrigação no desempenho agronômico de cultivares de arroz irrigado e na eficiência de uso da água, em várzeas tropicais. O estudo foi constituído por três experimentos: um, conduzido no Campo Experimental da Unitins, em Formoso do Araguaia, TO em Plintossolo Háplico distrófico; e dois experimentos foram realizados na Fazenda Palmital, da Embrapa Arroz e Feijão, no município de Goianira, GO, em Gleissolo Háplico distrófico. Foram avaliados quatro manejos de água: Inundação contínua - IC (método convencional, com lâmina de água contínua durante todo ciclo); Irrigação intermitente em todo ciclo - II; Irrigação intermitente até a floração, após contínua - IIF e Solo saturado - SS (solo mantido acima da capacidade de campo, mas sem lâmina de água), e quatro cultivares BRS Pampeira, BRS Catiana, BRS A702 CL e IRGA 424. O delineamento experimental usado foi o inteiramente casualizado, com cinco repetições, no esquema de parcelas divididas, constituídas pelos quatro manejos de água, e as subparcelas pelas cultivares. Os resultados mostraram que o manejo da irrigação solo saturado propicia produtividade média de grãos das cultivares de arroz irrigado similar ou superior em até $16 \%$ ao manejo tradicional de água com inundação contínua e com redução de até $82 \%$ do volume de água aplicado, o que resulta em maior eficiência de uso da água. O manejo solo saturado e irrigação intermitente constituem estratégias para racionalizar o uso dos recursos hídricos na orizicultura.

Palavras-chave: Oryza sativa L., inundação, cultivar, características agronômicas, produtividade de grãos.

\footnotetext{
${ }^{1}$ Eng. Agrônomo, Doutor em Agronomia, Embrapa Arroz e Feijão, Santo Antônio de Goiás, GO; alberto.baeta@embrapa.br*

2 Eng. Agrônomo, Doutor em Irrigação e Drenagem, Embrapa Arroz e Feijão, Santo Antônio de Goiás, GO; alexandre.heinemann@embrapa.br

${ }^{3}$ Eng. Agrônoma, Doutora em Agronomia, Embrapa Arroz e Feijão, Santo Antônio de Goiás, GO; mellissa.soler@embrapa.br

4 Eng. Agrônomo, Doutor em Solos e Nutrição de Plantas, Embrapa Arroz e Feijão, Santo Antônio de Goiás, GO; luis.stone@embrapa.br

5 Eng. Agrônomo, Mestre em Irrigação no Cerrado, Embrapa Arroz e Feijão, Santo Antônio de Goiás, GO; leandro.pimenta@embrapa.br

${ }^{6}$ Eng. Agrônomo, Mestre em Agronomia, Embrapa Pesca e Aquicultura, Palmas, TO; deivison.santos@embrapa.br
} 
Revista Agri-Environmental Sciences, v. 7, Ed. Especial, e021002, 2021

DOI: https://doi.org/10.36725/agries.v7i2.5294

https://revista.unitins.br/index.php/agri-environmental-sciences/index

Arroz.do

Tocantins

Arroz do Tocantins: no coração do Brasil

AGRIES

AGRI-ENVIRONMENTAL

Artigo Científico

ISSN 2525-4804

IRRIGATION MANAGEMENT ON IRRIGATED RICE CROP AND ON WATER USE EFFICIENCY IN TROPICAL FLOODPLAINS

\begin{abstract}
:
Appropriate irrigation water management is among the techniques necessary to achieve high productive potential in irrigated agricultural systems. The objective of this study was to determine the influence of irrigation management on the agronomic performance of irrigated rice cultivars and the water use efficiency in tropical floodplains. The study consisted of three experiments: The first was carried out at the Experimental Field of Unitins in Formoso do Araguaia, TO, in a Plinthosol and the second and third at the Palmital Farm of Embrapa Rice and Beans, in the municipality of Goianira, GO, in a Gleysol. Four water managements were evaluated: a) Continuous flooding - CI (conventional method, with continuous water depth throughout the cycle); b) Intermittent irrigation throughout the cycle - II; c) Intermittent irrigation until flowering, after continuous - IIF; and d) Saturated soil - SS (soil maintained above field capacity, but without water depth), and the cultivars BRS Pampeira, BRS Catiana, BRS A702 CL and IRGA 424. The experimental design used was completely randomized, with five replications, in the split-plot scheme consisting of the four water managements, and the subplots by the cultivars. Results showed that saturated soil provides an average grain yield similar or higher of up to $16 \%$ of irrigated rice cultivars in relation to traditional water management with continuous flooding, reducing up to $82 \%$ in the volume of water applied, which results in greater water use efficiency. Thus, saturated soil and intermittent irrigation are strategies to rationalize water resources in rice growing.
\end{abstract}

Keywords: Oryza sativa L., flooding, cultivar, agronomic traits, grain yield. 


\section{INTRODUÇÃO}

Na região tropical, o ecossistema várzea, com destaque para o vale do Tocantins-Araguaia, apresenta condições favoráveis para produção de culturas alimentares como o arroz irrigado, em razão de sua extensão, topografia e disponibilidade de água, desde que respeitadas as restrições legais (Santos et al., 2015; 2020).

A racionalização do uso de água é fundamental para produzir alimentos de maneira sustentável (Alberto et al., 2020). Conforme a Política Nacional de Recursos Hídricos (lei 9433, 1997), a água é um recurso natural limitado e dotado de valor econômico. Então, em situações de escassez, seu uso prioritário deve ser para o consumo humano e dessedentação animal.

Em razão das mudanças do clima e do aumento da frequência de eventos hidrológicos extremos, que afetam a disponibilidade de água, de maneira constante, para a população (Pagnoccheschi et al., 2010) e, que impactam sobremaneira as demandas associadas à geração de energia elétrica e consumo industrial, aumentar a eficiência do uso da água na agricultura, produzindo uma maior quantidade de alimentos por volume de água utilizado, deve ser objetivo prioritário dos sistemas agrícolas irrigados.

O arroz é alimento básico de mais da metade da população mundial, ou seja, mais de 3,5 bilhões de pessoas dependem do arroz para mais de $20 \%$ de sua ingestão calórica diária (GRiSP, 2013; CGIAR, 2021). Foi estimado que, para cada bilhão de pessoas a mais na população mundial, serão necessários mais 100 milhões de toneladas de arroz por ano (CGIAR, 2021). Atualmente, os sistemas irrigados ainda são garantidores de melhores produtividades, por isso são responsáveis pela maior parte dessa produção de grãos. Além disso, enquanto a agricultura utiliza cerca de $70 \%$ do suprimento de água doce do planeta, cerca de $40 \%$ desse montante tem sido direcionado ao cultivo de arroz (Yadav et al., 2018), tornando-se mandatório o desenvolvimento e utilização de sistemas agrícolas mais eficientes no uso da água. Assim, garantir a sustentabilidade da orizicultura deve ser prioridade para ma a população mundial em crescente aumento, mantendo a segurança alimentar, o crescimento econômico, a qualidade de vida e a estabilidade social (Yadav et al., 2018).

No manejo da irrigação com lâmina contínua, sem intervalos de oxidação, Santos et al. (2017) relataram que, para cultivar que apresenta maior crescimento inicial, a inundação deve preceder ou ocorrer no início do perfilhamento. Enquanto para cultivar de crescimento mais lento, a lâmina de água pode ser estabelecida até meados do perfilhamento. Esse é um método de irrigação tradicional por superfície e é amplamente usado nas regiões de grande representatividade da cultura do arroz irrigado, como o Sul do Brasil. No entanto, na região tropical, sua adoção é dificultada em razão da diferença das propriedades do solo, em especial a permeabilidade, clima e diversidade de atributos das bacias hidrográficas, particularmente pela alteração sazonal do nível freático (Santos et al., 2015; 2020).

$\mathrm{O}$ volume de água requerido pela cultura de arroz irrigado por inundação está relacionado àquele necessário para que as plantas cresçam e transpirem. Entretanto, a quantidade total de água necessária para atender a lavoura de arroz tem outros componentes, como a água necessária para a saturação do solo, formação da lâmina, perdas laterais e por percolação. Com isso, a quantidade depende das condições climáticas, manejo da cultura, atributos físicos do solo, dimensões e revestimento dos canais, ciclo da cultivar, localização da fonte e profundidade do lençol freático (Stone, 2005; Gomes et al., 2008; REUNIÃO, 2018).

O elevado custo da irrigação da lavoura de arroz, associado à menor disponibilidade dos recursos hídricos ao longo dos anos, tornaram a 
racionalização do uso da água uma meta a ser atingida, mediante a adoção de manejos alternativos da irrigação. Com base na demanda hídrica da cultura de arroz, pesquisas têm sido conduzidas na busca por alternativas de manejo para aumentar a Eficiência de Uso da Água (EUA), que consiste na adoção de novos manejos de água em substituição ao convencional de irrigação por inundação contínua. Nesse aspecto, têm-se destacado a irrigação de lâmina variável ou intermitente e a saturação do solo.

No manejo, denominado irrigação por inundação contínua com fornecimento intermitente, o solo permanece com lâmina de água ou pelo menos saturado durante todo o ciclo da cultura, alterando a química do solo por meio da introdução de períodos aeróbios durante o ciclo da cultura (Linquist et al., 2015). Isso pode levar ao menor consumo de água e, conforme já observado por diversos autores (STONE et al., 1990; SANTOS et al., 2003; 2015; ÁVILA, et al., 2015; HOWELL et al., 2015; CARRIJO et al., 2017), sem decréscimo na produtividade, indicando que o manejo apropriado da água de irrigação pode contribuir para aumentar e sustentar a produção orizícola a longo prazo.

Nas áreas alagadas da região Sul do país, o fornecimento de água para as lavouras se dá, majoritariamente, por meio de bombeamento direto dos cursos d'água. Nas várzeas do estado do Tocantins, o fornecimento para as lavouras ocorre por meio da elevação do lençol freático que, por sua vez, depende do nível de água dos rios o qual é fortemente afetado pelo regime de chuvas.

Objetivou-se com este estudo determinar os efeitos do manejo da irrigação no desempenho agronômico de cultivares de arroz irrigado e na eficiência de uso da água, em várzeas tropicais.

\section{MATERIAL E MÉTODOS}

O estudo foi conduzido por três safras agrícolas, em duas áreas experimentais. A primeira (safra 2015/16), conduzida no Campo Experimental da Unitins, em Formoso do Araguaia, TO, latitude $11^{\circ} 47^{\prime} 49^{\prime \prime} \mathrm{S}$, longitude 49 31'44" W, altitude $130 \mathrm{~m}$, em um Plintossolo Háplico distrófico. E a segunda área (safras 2016/17 e 2017/18), na Fazenda Palmital, da Embrapa Arroz e Feijão, no município de Goianira, GO, latitude $16^{\circ} 26^{\prime} 20^{\prime \prime} \mathrm{S}$, longitude $49^{\circ} 23^{\prime} 45^{\prime \prime} \mathrm{W}$, altitude $728 \mathrm{~m}$, em Gleissolo Háplico distrófico, textura média a média/arenosa (Santos et al., 2018).

Foram avaliados quatro manejos de água: Inundação contínua - IC (método convencional, com lâmina de água contínua durante todo ciclo); Irrigação intermitente em todo ciclo - II; Irrigação intermitente até a floração, após contínua - IIF e Solo saturado - SS (solo mantido acima da capacidade de campo, mas sem lâmina de água), e quatro cultivares BRS Pampeira, BRS Catiana, BRS A702 CL e IRGA 424. O delineamento experimental usado foi $\mathrm{O}$ inteiramente casualizado, com cinco repetições, no esquema de parcelas divididas constituídas pelos quatro manejos de água, com $400 \mathrm{~m}^{2}$, e as subparcelas pelas cultivares, com $100 \mathrm{~m}^{2}$.

Constam, na Tabela 1, os atributos químicos das amostras de solo das áreas experimentais coletadas no início do estudo.

Em Formoso do Araguaia, TO, na safra $2015 / 16$, a semeadura foi realizada em $06 / 11 / 15$ e a adubação de base foi o equivalente a $10 \mathrm{~kg} \mathrm{ha}$ ${ }^{1}$ de N, $40 \mathrm{~kg} \mathrm{ha}^{-1}$ de $\mathrm{P}_{2} \mathrm{O}_{5}$ e $50 \mathrm{~kg} \mathrm{ha}^{-1}$ de $\mathrm{K}_{2} \mathrm{O}$. A germinação ocorreu em 11/11/2015. Na safra 2016/2017, em Goianira, GO, as cultivares foram semeadas em 10/10/2016 e a adubação de base foi o equivalente a $20 \mathrm{~kg} \mathrm{ha}^{-1} \mathrm{de} \mathrm{N}, 40 \mathrm{~kg} \mathrm{ha}^{-1}$ de $\mathrm{P}_{2} \mathrm{O}_{5}$ e $50 \mathrm{~kg} \mathrm{ha}^{-1}$ de $\mathrm{K}_{2} \mathrm{O}$. A germinação ocorreu em 21/10/2016. No segundo ano, em Goianira, GO, safra 2017/18, as cultivares foram semeadas em 27/10/2017 e a adubação de base foi o equivalente a $20 \mathrm{~kg} \mathrm{ha}^{-1}$ de $\mathrm{N}, 35 \mathrm{~kg} \mathrm{ha}^{-1} \mathrm{de}_{2} \mathrm{P}_{2} \mathrm{O}_{5}$ e $35 \mathrm{~kg} \mathrm{ha}^{-1}$ de $\mathrm{K}_{2} \mathrm{O}$. A germinação ocorreu em 06/11/2017. Nos três experimentos, as adubações nitrogenadas em cobertura foram realizadas nas 
fases de desenvolvimento V3-V4 $\left(30 \mathrm{~kg} \mathrm{ha}^{-1}\right.$ de $\mathrm{N})$ e em V6-V7 (50 $\mathrm{kg} \mathrm{ha}^{-1} \mathrm{de} \mathrm{N}$ ). Foi empregado o sistema de semeadura em linhas, espaçadas de $0,17 \mathrm{~m}$ com 80 sementes por metro. Por ocasião da semeadura, efetuaram-se as adubações com base nas análises dos solos. A competição com as plantas daninhas foi prevenida com a aplicação do herbicida oxidiazon $\left(0,8 \mathrm{~kg} \mathrm{ha}^{-1}\right.$ i.a. $)$, em préemergência.

Tabela 1. Atributos químicos de amostras dos solos das áreas experimentais, no início do estudo.

\begin{tabular}{|c|c|c|c|c|c|c|c|c|c|c|c|c|}
\hline \multirow[t]{2}{*}{ Local / Safra } & pH & $\mathrm{Ca}$ & Mg & Al & $\mathbf{H}+\mathbf{A l}$ & $\mathbf{P}$ & $\mathbf{K}$ & $\mathbf{C u}$ & Zn & $\mathbf{F e}$ & Mn & \multirow{2}{*}{$\begin{array}{c}\text { M.O. } \\
\text { g/kg }\end{array}$} \\
\hline & $\left(\mathrm{H}_{2} \mathrm{O}\right)$ & \multicolumn{4}{|c|}{ mmolc/dm 3} & \multicolumn{6}{|c|}{$\mathrm{mg} / \mathrm{dm}^{3}$} & \\
\hline $\begin{array}{c}\text { Formoso do } \\
\text { Araguaia, TO } \\
2015 / 16\end{array}$ & 5,4 & 21,8 & 12,4 & 1,1 & 24,9 & 17,9 & 64,4 & 1,7 & 5,1 & 70 & 42,8 & 43,1 \\
\hline $\begin{array}{c}\text { Goianira, GO } \\
2016 / 17\end{array}$ & 5,1 & 8,7 & 4,1 & 7,5 & 58,5 & 23,1 & 52,0 & 2,6 & 3,8 & 329 & 15,2 & 16,3 \\
\hline $\begin{array}{c}\text { Goianira, GO } \\
2017 / 18\end{array}$ & 4,8 & 12,4 & 4,5 & 9,5 & 36,8 & 35,6 & 45,5 & 2,8 & 4,0 & 339 & 13,3 & 20,9 \\
\hline
\end{tabular}

Nos três primeiros manejos, a lâmina de água foi aplicada no estádio de desenvolvimento vegetativo V3 - V4, ou seja, formação do colar na $3^{\mathrm{a}}$ ou $4^{\mathrm{a}}$ folha do colmo principal, precedendo ou no início do perfilhamento. No manejo inundação contínua, durante o período de irrigação, foi mantida lâmina de água uniforme de cerca de 0,10 m. Nos manejos irrigação com intermitência, a lâmina era reposta quando ela desaparecia da superfície do solo. Ou seja, a água de irrigação era reaplicada, quando a condição hídrica do solo se aproximava da saturação nos primeiros $0,20 \mathrm{~m}$ de profundidade do solo. A supressão da irrigação ocorreu no estádio R8 - R9 - maturação completa dos grãos.

A quantidade de água utilizada na irrigação foi monitorada mediante o uso de hidrômetros e a água proveniente da precipitação foi mensurada pela estação meteorológica. Isso possibilitou a determinação da eficiência do uso da água (EUA), em $\mathrm{kg} \mathrm{m}^{-3}$, que foi calculada dividindo a produtividade, em $\mathrm{kg} \mathrm{ha}^{-1}$, pelo total de água usada (água da irrigação e água da precipitação, $\mathrm{m}^{3}$ ).
Por ocasião da colheita, foi determinada a altura de plantas, e em seguida realizaram-se amostragens de plantas em seis linhas de 2,5 m, as quais foram separadas em palha, composta de folhas, bainhas e colmos, e grãos. Após secagem, foram determinados a massa da matéria seca de palha $\left(\mathrm{g} \mathrm{m}^{-2}\right)$ e massa total da parte aérea $\left(\mathrm{g} \mathrm{m}^{-2}\right)$. Foram determinados os componentes da produtividade: índice de colheita de grãos, número de grãos, número de espiguetas vazias, massa de 100 grãos, e a produtividade de grãos $\left(\mathrm{kg} \mathrm{ha}^{-1}\right)$, após a umidade ser ajustada para $13 \%$. O índice de colheita de grãos (ICG) foi obtido pela relação entre a produção de grãos e a massa da matéria seca total em $1 \mathrm{~m}^{2}$, dado em $\mathrm{g} \mathrm{m}^{-2}$. Foram coletadas dez panículas para determinação do número de grãos e de espiguetas vazias e da massa de grãos.

Os dados foram submetidos à análise de variância, com o auxílio do programa estatístico Sisvar (FERREIRA, 2014), e a discriminação entre os manejos de água e as cultivares foi realizada por teste de médias (Tukey. $\mathrm{p}<0,05$ ). 


\section{RESULTADOS E DISCUSSÃO}

Dada a interação significativa da produtividade de grãos de arroz irrigado entre manejos de água e cultivares em cada experimento, houve necessidade de se fazer a discussão por safra e local, uma vez que não foi observada interação tripla (safra $\mathrm{x}$ manejo de água $\mathrm{x}$ cultivar). Essa interação safra $\mathrm{x}$ local indica que o desempenho das cultivares de arroz diferiu em cada experimento, o que pode ser atribuído à variabilidade do ambiente. Isso enfatiza a importância de se avaliar os efeitos dos manejos da cultura sobre a produtividade de grãos, em várias safras.

Nas várzeas em Formoso do Araguaia, TO, onde as condições climáticas, como temperaturas máximas do ar e da água são mais elevadas do que as observadas no município de Goianira, GO, as cultivares apresentaram produtividades de grãos distintas em relação aos manejos da água (Tabela 2). De modo geral, as cultivares de arroz irrigado apresentaram melhores desempenhos agronômicos nos manejos que demandaram menores volumes de água. A produtividade de grãos da cultivar BRS Pampeira foi maior no manejo solo saturado e a da BRS Catiana com a irrigação intermitente. A cultivar BRS A702 CL apresentou menor produtividade de grãos com a inundação contínua durante todo ciclo, enquanto a IRGA 424 não foi influenciada pelos manejos de água.

Em relação ao manejo convencional, o manejo da irrigação com o solo saturado incrementou a produtividade média de grãos das cultivares de arroz irrigado em 12\% (Tabela 2). Em estudo conduzido também na região tropical, no município de Dueré, TO, por dois anos consecutivos, Santos et al. (2003) observaram que a manutenção de lâmina contínua por todo o ciclo promoveu menor produtividade do que aquelas obtidas em manejo do solo saturado durante todo o ciclo e irrigação intermitente com lâmina até a floração em todas cultivares. Segundo esses autores, a menor produtividade de grãos na presença da lâmina contínua foi em razão da ocorrência de altas temperaturas da água de irrigação durante o ciclo da cultura, afetando severamente o enchimento de grãos.

Tabela 2. Interação entre cultivar e manejo de água na produtividade de grãos de arroz irrigado, Formoso do Araguaia, TO, safra 2015/16.

\begin{tabular}{cccccc}
\hline & \multicolumn{5}{c}{ Cultivar } \\
\cline { 2 - 5 } Manejo de água $^{1}$ & $\begin{array}{c}\text { BRS } \\
\text { Pampeira }\end{array}$ & $\begin{array}{c}\text { BRS } \\
\text { Catiana }\end{array}$ & $\begin{array}{c}\text { BRS } \\
\text { A702 CL }\end{array}$ & $\begin{array}{c}\text { IRGA } \\
\mathbf{4 2 4}\end{array}$ & Média \\
\cline { 2 - 5 } & \multicolumn{5}{c}{ Produtividade de grãos $\left(\mathbf{k g ~ h a}^{-\mathbf{1}}\right)$} \\
SS & $6994 \mathrm{a}^{2}$ & $6030 \mathrm{bc}$ & $6624 \mathrm{a}$ & $5510 \mathrm{a}$ & 6290 \\
IC & $5577 \mathrm{~b}$ & $5475 \mathrm{c}$ & $5404 \mathrm{~b}$ & $6012 \mathrm{a}$ & 5617 \\
II & $5631 \mathrm{~b}$ & $6964 \mathrm{ab}$ & $6939 \mathrm{a}$ & $6643 \mathrm{a}$ & 6544 \\
IIF & $5960 \mathrm{ab}$ & $7225 \mathrm{a}$ & $6981 \mathrm{a}$ & $6076 \mathrm{a}$ & 6561 \\
\hline Média & 6041 & 6424 & 6487 & 6060 & \\
\hline
\end{tabular}

${ }^{1}$ SS Solo saturado; IC Inundação contínua; II Irrigação intermitente; IIF Irrigação intermitente até a floração, após contínua. ${ }^{2}$ Médias seguidas por letras distintas, na coluna, diferem entre si, pelo teste de Tukey $(\mathrm{P} \leq 0,05)$. 
Em Goianira, GO, as características agronômicas das cultivares de arroz irrigado, como altura de plantas, índice de colheita de grãos e número de grãos por panículas tiveram desempenhos distintos em razão dos manejos da água de irrigação, nos dois anos de cultivo. Enquanto o número de panículas por área e a biomassa não diferiram, no segundo ano (Tabela 3). As maiores alturas de plantas foram observadas no manejo inundação contínua em todo ciclo. Plantas mais altas no manejo que mantém a lâmina de água durante o ciclo também foram verificadas no estudo de Santos et al. (2003).

De acordo com Alberto et al. (2020), lâminas de água acima de $0,10 \mathrm{~m}$ podem ocasionar redução no perfilhamento e estiolamento das plantas nos estádios iniciais, aumentando a altura de plantas e, consequentemente, as chances de ocorrer acamamento. O número de panículas por área que, segundo Fageria (2007) é o mais importante componente da produtividade do arroz, não diferiu entre os manejos sob inundação contínua e solo saturado. Ao contrário dos resultados observados em vários estudos desenvolvidos em ambientes tropicais (STONE et al., 1990; SANTOS et al., 1999; 2003; 2015), em que a presença da lâmina de água contínua durante a fase vegetativa inibiu o perfilhamento. Contudo esses resultados estão de acordo com estudos conduzidos na China, em que o manejo de água na cultura do arroz foi realizado por meio de elevação de lençol freático em sistema intermitente com lâmina rasa e propiciou maior absorção de N pelas plantas (Qi et al., 2020).

Na safra 2016/17, os maiores índices de colheita de grãos foram verificados nos manejos que demandaram menores quantidades de água, quais sejam, solo saturado $(0,56)$ e irrigação intermitente $(0,54)$ (Tabela 3). As cultivares, atualmente usadas no sistema de cultivo de arroz irrigado, apresentam índice de colheita de grãos ao redor de 0,50. Maior índice de colheita de grãos significa maior eficiência de translocação dos produtos da fotossíntese para as partes economicamente importantes da planta e, em consequência, incremento na produtividade de grãos. Correlação positiva do índice de colheita de grãos com a produtividade de grãos de arroz irrigado foi relatada em diversos estudos desenvolvidos na região tropical (Fageria, 2007; Fageria et al., 2011; Fageria \& Santos, 2015). Considerando-se esses resultados, a seleção de plantas, por meio de programas de melhoramento genético para maiores índices de colheita de grãos, poderia ser uma forma eficiente para aumentar a produtividade de grãos.

A massa da matéria seca da parte aérea e o número de grãos por panícula das cultivares não tiveram desempenhos definidos com relação aos manejos de água. Entre as cultivares, a BRS Pampeira foi a mais alta e apresentou maior número de grãos por panícula, nos dois anos. 
Tabela 3. Características agronômicas de cultivares de arroz irrigado influenciadas pelo manejo da água, Goianira, GO, nos dois anos.

\begin{tabular}{|c|c|c|c|c|c|}
\hline Manejo da água $^{1}$ & $\begin{array}{l}\text { Altura de plantas } \\
\qquad(\mathrm{cm})\end{array}$ & $\begin{array}{c}\text { Panícula } \\
\left(n^{0} \mathbf{m}^{-2}\right)\end{array}$ & $\begin{array}{c}\text { Biomassa } \\
\left(\mathrm{g} \mathrm{m}^{-2}\right)\end{array}$ & $\mathrm{ICG}^{2}$ & $\begin{array}{c}\text { Grãos } \\
\left(\mathbf{n}^{\mathbf{o}} \text { pan. }^{-1}\right)\end{array}$ \\
\hline \multicolumn{6}{|c|}{ Safra 2016/17 } \\
\hline SS & $81 b^{3}$ & $650 \mathrm{a}$ & $1628 \mathrm{a}$ & $0,56 a$ & $83 a$ \\
\hline IC & $83 a$ & $588 \mathrm{ab}$ & $1491 \mathrm{ab}$ & $0,53 b$ & $77 \mathrm{ab}$ \\
\hline II & $80 \mathrm{~b}$ & $554 b$ & $1429 b$ & $0,54 a b$ & $75 \mathrm{ab}$ \\
\hline IIF & $80 \mathrm{~b}$ & $594 \mathrm{ab}$ & $1488 \mathrm{ab}$ & $0,53 b$ & $72 b$ \\
\hline \multicolumn{6}{|c|}{ Cultivar } \\
\hline BRS Pampeira & $87 \mathrm{a}$ & $575 \mathrm{ab}$ & $1644 a$ & $0,53 b$ & $83 a$ \\
\hline BRS Catiana & $82 b$ & $646 a$ & $1537 \mathrm{ab}$ & $0,54 \mathrm{ab}$ & $74 b c$ \\
\hline BRS 702CL & $81 b$ & $523 b$ & $1452 b$ & $0,54 \mathrm{ab}$ & $82 \mathrm{ab}$ \\
\hline IRGA 424 & $76 \mathrm{c}$ & $642 a$ & $1402 b$ & $0,56 \mathrm{a}$ & $67 \mathrm{c}$ \\
\hline Média & 81 & 597 & 1509 & 0,54 & 77 \\
\hline C.V. (\%) & 3,65 & 16,98 & 13,84 & 3,58 & 13,40 \\
\hline \multicolumn{6}{|c|}{ Safra 2017/18 } \\
\hline SS & $81 b$ & $606 a$ & $1439 a$ & $0,55 \mathrm{ab}$ & $101 \mathrm{a}$ \\
\hline IC & $84 a$ & $587 \mathrm{a}$ & $1475 a$ & $0,56 a b$ & $98 \mathrm{a}$ \\
\hline II & $81 b$ & $569 \mathrm{a}$ & $1374 a$ & $0,57 \mathrm{a}$ & $96 a b$ \\
\hline IIF & $78 \mathrm{c}$ & $628 \mathrm{a}$ & $1394 a$ & $0,54 b$ & $89 b$ \\
\hline \multicolumn{6}{|c|}{ Cultivar } \\
\hline BRS Pampeira & $87 \mathrm{a}$ & $606 a b$ & $1512 \mathrm{a}$ & $0,55 \mathrm{ab}$ & $109 a$ \\
\hline BRS Catiana & $82 b$ & $579 b$ & $1393 a$ & $0,57 \mathrm{a}$ & $97 b$ \\
\hline BRS 702CL & $79 \mathrm{c}$ & $535 b$ & $1418 \mathrm{a}$ & $0,54 b$ & $101 b$ \\
\hline IRGA 424 & $77 \mathrm{c}$ & $670 \mathrm{a}$ & $1359 a$ & $0,55 \mathrm{ab}$ & $77 \mathrm{c}$ \\
\hline Média & 81 & 598 & 1420 & 0,55 & 96 \\
\hline C.V. (\%) & 3,11 & 15,47 & 19,07 & 6,02 & 9,66 \\
\hline
\end{tabular}

${ }^{1}$ SS Solo saturado; IC Inundação contínua; II Irrigação intermitente; IIF Irrigação intermitente até a floração, após contínua. ${ }^{2}$ Índice de colheita de grãos. ${ }^{3}$ Médias seguidas por letras distintas, na coluna, diferem entre si, pelo teste de Tukey $(\mathrm{P} \leq 0,05)$. 
Em Goianira, na safra 2016/17, a cultivar BRS Catiana de arroz irrigado apresentou maior produtividade de grãos com o solo saturado, em relação ao manejo inundação contínua, enquanto que as produtividades da BRS Pampeira e BRS A702 CL foram similares nos dois manejos (Tabela 4). A produtividade de grãos da cultivar IRGA 424 não diferiu com os manejos de água, nos dois anos. $\mathrm{O}$ incremento médio de produtividade de grãos das cultivares obtido no primeiro ano com o manejo alternativo solo saturado foi de $16 \%$, em relação ao manejo convencional. Isso, aliado ao menor uso da água, resulta em maior sustentabilidade do sistema de cultivo de arroz irrigado. Reis et al. (2018) e Qi et al. (2020), ao compararem regimes alternativos de irrigação, relataram que manejos de irrigação que demandam menor volume de água aplicado propiciam aumento da eficiência do uso de nitrogênio, minimizando sua volatilização e lixiviação. Na segunda safra, apenas a cultivar BRS Catiana apresentou diferença significativa na produtividade de grãos em razão dos manejos de água, sendo mais produtiva no manejo que demanda maior volume de água, inundação contínua durante todo ciclo. Nos dois locais de condução do estudo, Formoso do Araguaia, TO, e Goianira, GO, a cultivar IRGA 424 não foi afetada pelos manejos de água.

Tabela 4. Interação entre cultivar e manejo de água na produtividade de grãos de arroz irrigado, Goianira, GO, nos dois anos.

\section{Cultivar}

\begin{tabular}{llllll} 
Manejo de água $^{1}$ & BRS Pampeira & BRS Catiana & BRS A702 CL & IRGA 424 & Média \\
\cline { 2 - 4 } & \multicolumn{4}{c}{ Produtividade de grãos $\left(\mathrm{kg} \mathrm{ha}^{-1}\right)$}
\end{tabular}

\begin{tabular}{cccccc}
\hline \multicolumn{5}{c}{ Safra 2016/17 } \\
\hline SS & $7922 \mathrm{a}^{2}$ & $8133 \mathrm{a}$ & $7618 \mathrm{a}$ & $7400 \mathrm{a}$ & 7768 \\
IC & $7070 \mathrm{ab}$ & $6910 \mathrm{~b}$ & $6646 \mathrm{ab}$ & $6285 \mathrm{a}$ & 6728 \\
II & $6522 \mathrm{~b}$ & $6951 \mathrm{ab}$ & $6563 \mathrm{ab}$ & $6537 \mathrm{a}$ & 6643 \\
IIF & $6581 \mathrm{~b}$ & $6723 \mathrm{~b}$ & $6408 \mathrm{~b}$ & $6536 \mathrm{a}$ & 6562 \\
\hline Média & 7024 & 7179 & 6809 & 6690 & \\
\hline SS & Safra 2017/18 & & & \\
\hline IC & $5754 \mathrm{a}$ & $5359 \mathrm{~b}$ & $6644 \mathrm{a}$ & $5954 \mathrm{a}$ & 5928 \\
II & $6678 \mathrm{a}$ & $7312 \mathrm{a}$ & $6946 \mathrm{a}$ & $5724 \mathrm{a}$ & 6665 \\
IIF & $6670 \mathrm{a}$ & $5300 \mathrm{~b}$ & $5923 \mathrm{a}$ & $6921 \mathrm{a}$ & 6203 \\
\hline Média & $5546 \mathrm{a}$ & $5696 \mathrm{~b}$ & $6544 \mathrm{a}$ & $5373 \mathrm{a}$ & 5790 \\
\hline ISS Sol & 6162 & 5917 & 6514 & 5993 & \\
\hline
\end{tabular}

${ }^{1}$ SS Solo saturado; IC Inundação contínua; II Irrigação intermitente; IIF Irrigação intermitente até a floração, após contínua. ${ }^{2}$ Médias seguidas por letras distintas, na coluna, diferem entre si, pelo teste de Tukey $(\mathrm{P} \leq 0,05)$. 
Nas duas safras, os maiores volumes de água foram aplicados no manejo de irrigação convencional, lâmina contínua $\left(27624 \mathrm{~m}^{3} \mathrm{ha}^{-1}\right)$, seguidos pelos manejos irrigação intermitente até a floração após contínua (21194 $\mathrm{m}^{3} \mathrm{ha}^{-1}$ ), irrigação intermitente em todo ciclo $\left(19938 \mathrm{~m}^{3}\right.$ $\left.\mathrm{ha}^{-1}\right)$ e solo saturado (10924 $\left.\mathrm{m}^{3} \mathrm{ha}^{-1}\right)$, concordando com Reis et al. (2018). O elevado requerimento de água verificado sob inundação contínua foi devido às maiores perdas por percolação e fluxo lateral, em virtude do alto teor de areia do solo, ao redor de $50 \%$. A percolação excessiva pode acarretar lixiviação de nutrientes, especialmente nitrogênio e potássio. Na safra 2016/17, o manejo que demandou menor quantidade de água, em solo saturado propiciou a maior produtividade média de grãos das cultivares, o que refletiu na maior EUA (Tabela 5).

Tabela 5. Produtividade de grãos de arroz irrigado, volume de água aplicado e eficiência de uso da água (EUA), em razão do manejo de água, Goianira, GO, nos dois anos.

\begin{tabular}{|c|c|c|c|}
\hline Manejo de água ${ }^{1}$ & $\begin{array}{c}\text { Produtividade de grãos } \\
\qquad\left(\mathrm{kg} \mathrm{ha}^{-1}\right)\end{array}$ & $\begin{array}{l}\text { Volume de água aplicado } \\
\qquad\left(\mathrm{m}^{3} \mathbf{h a}^{-1}\right)\end{array}$ & $\begin{array}{c}\text { EUA } \\
\left(\mathrm{kg} \mathrm{m}^{-3}\right)\end{array}$ \\
\hline \multicolumn{4}{|c|}{ Safra 2016/17 } \\
\hline $\mathrm{SS}$ & $7768 a^{3}$ & 10924 & 0,71 \\
\hline IC & $6728 b$ & 27624 & 0,24 \\
\hline II & $6643 b$ & 19938 & 0,33 \\
\hline IIF & $6562 b$ & 21194 & 0,31 \\
\hline \multicolumn{4}{|c|}{ Safra 2017/18 } \\
\hline SS & $5928 \mathrm{ab}$ & 9882 & 0,60 \\
\hline IC & $6665 a$ & 54778 & 0,12 \\
\hline II & $6203 \mathrm{ab}$ & 31669 & 0,20 \\
\hline IIF & $5790 \mathrm{~b}$ & 42543 & 0,14 \\
\hline
\end{tabular}

${ }^{1}$ SS Solo saturado; IC Inundação contínua; II Irrigação intermitente; IIF Irrigação intermitente até a floração, após contínua. ${ }^{2}$ Média de quatro cultivares. ${ }^{3}$ Médias seguidas por letras distintas, na coluna, diferem entre si, pelo teste de Tukey $(\mathrm{P} \leq 0,05)$.

Reis et al. (2018) e Qi et al. (2020) atribuíram maiores produtividades de grãos no sistema aeróbico à maior absorção e recuperação de N. Um dos principais aspectos relacionados à sustentabilidade na agricultura consiste em maximizar a EUA, mediante o aumento da produtividade da água $\left(\mathrm{kg}\right.$ arroz $\mathrm{m}^{-3}$ de água aplicado) (Santos et al., 2015, 2020; Alberto et al., 2020). Os volumes de água aplicados nos manejos solo saturado, irrigação intermitente durante o ciclo e intermitente até a floração foram $61 \%, 28 \%$ e $23 \%$ menores, respectivamente, que o aplicado na inundação contínua. Com isso, a EUA passou de $0,24 \mathrm{~kg} \mathrm{~m}^{-3}$ nesse manejo para $0,71,0,33$ e $0,31 \mathrm{~kg}$ de grãos por metro cúbico de água nos três manejos, respectivamente (Tabela $5)$.

A não manutenção da lâmina de água durante o ciclo, na safra 2017/18, propiciou produtividades médias de grãos das cultivares de 
arroz irrigado equivalentes à obtida com a inundação contínua em todo ciclo, o que refletiu no aumento da EUA. Os volumes de água aplicados nos manejos solo saturado, irrigação intermitente durante o ciclo e intermitente até a floração foram 82, 42 e 22\% menores, respectivamente, que com a inundação contínua (Tabela 5). Com isso, a EUA passou de 0,12 nesse manejo para $0,60,0,20$ e $0,14 \mathrm{~kg}$ de grãos por metro cúbico de água nos três manejos, respectivamente. As maiores EUA nos manejos solo saturado e irrigação intermitente, contudo, estão condicionadas ao adequado intervalo de tempo entre o desaparecimento da lâmina de água do tabuleiro e a sua reposição. Yang et al (2017) consideram que a condição de secagem na inundação intermitente é o fator mais importante que afeta a produtividade do arroz. A inundação intermitente moderada, em que a fotossíntese não é inibida durante o período de secagem do solo e as plantas possam se reidratar durante a noite, pode não apenas economizar água, mas também aumentar a produtividade de grãos e a EUA, em relação à inundação contínua. Comparando os manejos de água convencional e intermitente, na região subtropical, Gomes et al. (2008) e Ávila et al. (2015) não verificaram diferença na produtividade de grãos e, com isso, também observaram aumento da EUA em arroz irrigado.

\section{CONCLUSÕES}

No cultivo de arroz irrigado, o manejo da irrigação solo saturado propicia produtividade de grãos similar ou superior ao manejo tradicional de água com inundação contínua ou intermitente, com maior eficiência de uso da água.

O manejo solo saturado e irrigação intermitente constituem estratégias para racionalizar o uso dos recursos hídricos na orizicultura.

\section{AGRADECIMENTOS}

Este estudo é parte dos experimentos desenvolvidos sob parceria internacional por meio do projeto "NUCLEUS: a virtual joint center to deliver enhanced NUE via na integrated soil-plant system approach for the United Kingdom and Brazil". Os autores agradecem a Fundação de Amparo à Pesquisa do Estado de Goiás (FAPEG: 2015-10267001479), a Fundação de Amparo à Pesquisa do Estado de São Paulo (FAPESP: 2015/50305-8), a Fundação de Amparo à Pesquisa do Estado do Maranhão (FAPEMA: RCUK-02771/16), e, no Reino Unido, ao Biotechnology and Biological Sciences Research Council (BBSRC: BB/N013201/1), sob o esquema Newton Fund, pelo apoio financeiro. Agradecem também à Empresa Brasileira de Pesquisa Agropecuária (Embrapa), pelo apoio técnico e financeiro. Ao Conselho Nacional de Desenvolvimento Científico e Tecnológico (CNPq) pelo suporte financeiro e pelas bolsas de Iniciação Científica e de Produtividade em Pesquisa concedidas.

\section{REFERÊNCIAS BIBLIOGRÁFICAS}

Alberto, C.M. Porta, F.S.D.; Garrido, G.C.; Zanon, A.J.; Poersh, A.H.; Duarte Junior, A.J.; Ribeiro, B.S.M.R.; Ribas, G.G.; Rossato, I.G.; Pilecco, I.B.; Meus, L.D.; Silva, M.R. da; Nascimento, M. de F. do; Souza, P.M. de; Pereira, V.F.; Streck, N.A. (2020). Uso da água em arroz irrigado. In: Meus, L.D.; Silva, M.R. da; Ribas, G.G.; Zanon, A.J.; Rossato, I.G.; Pereira, V.F.; Pilecco, I.B.; Ribeiro, B.S.M.R.; Souza, P.M. de; Nascimento, M. de F. do; Poersh, A.H.; Duarte Junior, A.J.; Quintero, C.E.; Garrido, G.C.; Carmona, L. de C.; Streck, N.A (eds.) Ecofisiologia do arroz visando altas produtividades. Santa Maria: [s.n.], p. 145-164.

Avila, L.A. de; Martini, L.F.D.; Mezzomo, R.F.; Refatti, J.P.; Campos, R; Cezimbra, D.M.; Machado, S.L.O; Massey, J.H.; Carlesso, R.; Marchesan, E. (2015). Rice water use efficiency and yield under continuous and intermittent irrigation. Agronomy Journal, 107(2): 442-448. 
Carrijo, D. R.; Lundy, M.E.; Linquist, B.A. (2017). Rice yields, and water use under alternate wetting and drying irrigation: A meta-analysis. Field Crops Research, 203: 173-180.

CGIAR. The global staple; 2021 [cited $2021 \mathrm{Apr}$ 27]. https://ricepedia.org/rice-as-food/theglobal-staple-rice-consumers.

Fageria, N.K. (2007) Yield physiology of rice. Journal of Plant Nutrition, 30: 843-879. <http://dx.doi.org/10.1080/15226510701374831 $>$.

Fageria, N.K.; Santos, A.B. dos. (2015). Yield and yield components of lowland rice genotypes as influenced by nitrogen fertilization. Communications in Soil Science and Plant Analysis, 46: 1723-1735. http://dx.doi.org/10.1080/00103624.2015.10434 $\underline{43}>$.

Fageria, N.K.; Santos, A.B. dos; Coelho, A.M. (2011). Growth, yield and yield components of lowland rice as influenced by ammonium sulfate and urea fertilization. Journal of Plant Nutrition, 34: 371-386. $<$ http://dx.doi.org/10.1080/01904167.2011.5368 79>.

Ferreira, D.F. (2014). Sisvar: a guide for its bootstrap procedures in multiple comparisons. Ciência e Agrotecnolgia, Lavras, 38(2), 109-112. Gomes, A. da S. et al. (2008). Estratégias para o aumento da eficiência do uso da água pelo arroz: efeito de sistemas alternativos de irrigação. In: Congresso Nacional De Irigação E Drenagem, 18., Anais. São Mateus: ABID, 2008. 1.CDROM.

Howell, K.R.; Shrestha, P.; Dodd, I.C. (2015). Alternate wetting and drying irrigation maintained rice yields despite half the irrigation volume, but is currently unlikely to be adopted by smallholder lowland rice farmers in Nepal.Food and Energy Security, 4(2): 144157.
International Rice Research Institute GRiSP. (2013). Rice almanac. Los Baños (Philippines): 283 p.

Linquist BA, Anders MM, Adviento-Borbe MAA, Chaney RL, Nalley LL, da Rosa EFF, van Kessel C. (2015). Reducing greenhouse gas emissions, water use, and grain arsenic levels in rice systems. Global Change Biology. 21:40717. https://doi.org/10.1111/gcb.12701.

Pagnoccheschi, B.; Gondim Filho, J.G.C.;

Guimarães, V.S.; Barbosa, A.S.; Maranhão, N.; Viana, F.L.; Troger, F.H.; Lima Filho, R.A. (2010). Os efeitos das mudanças climáticas sobre os recursos hídricos: desafios para a gestão. Brasília, DF.

Qi, D., Wu, Q, Zhu, J. (2020). Nitrogen and phosphorus losses from paddy fields and the yield of rice with different water and nitrogen management practices. Scientific Reports. 10(1): 9734. https://doi.org/10.1038/s41598$\underline{020-66757-5}$

Reis, A.F. de B.; Almeida, R.E.M. de; Lago, B.C.; Trivelin, P.C.; Linquist, B.; Favarin, J.L. (2018). Aerobic rice system improves water productivity, nitrogen recovery and crop performance in Brazilian weathered lowland soil, Field Crops Research, 218(1): 59-68. https://doi.org/10.1016/j.fcr.2018.01.002.

REUNIÃO TÉCNICA DA CULTURA DO ARROZ IRRIGADO, 32, 2018. Farroupilha, Arroz irrigado: recomendações técnicas da pesquisa para o Sul do Brasil. Cachoeirinha: SOSBAI, 2018. 205 p. Disponível em:

<http://www.sosbai.com.br/docs/Boletim_RT_2 018.pdf>. Acesso em: 08 fev. 2021.

Santos, H.G. dos; Jacomine, P.K.T.; Anjos, L.H.C. dos; Oliveira, V.A. de; Lumbreras, J.F.; Coelho, M.R.; Almeida, J.A. de; Araujo Filho, J.C. de; Oliveira, J.B. de; Cunha, T.J.F. (2018). Sistema Brasileiro de Classificação de Solos. 5. ed. Brasília, DF: Embrapa.

Santos, A.B dos; Stone, L.F.; Heinemann, A.B.; Santos, T.P.B. (2017). Índices fisiológicos do arroz irrigado afetados pela inundação e 
fertilização nitrogenada. Revista Ceres, 64(2): 122-131. 10.1590/0034-737X201764020003

Santos, A.B. dos; Stone, L.F.; Silva, S.C. da. (2015). Estratégia de irrigação para a cultura do arroz na Região Tropical. Santo Antônio de Goiás: Embrapa Arroz e Feijão, 6 p. (Embrapa Arroz e Feijão. Comunicado técnico, 231). ID 33873

Santos, A.B. dos; Fageria, N.K.; Stone, L.F.; Santos, C. (1999). Manejo de água e de fertilizante potássico na cultura do arroz irrigado. Pesquisa Agropecuária Brasileira, Brasília, DF, 34(4): 565-573.

Santos, A.B. dos; Silva, M.A.S. da; Stone, L.F.; Heinemann, A.B. (2020). Arroz irrigado em clima tropical no Brasil. In: Meus, L.D... [et al.] (Ed.). Ecofisiologia do arroz visando altas produtividades. Santa Maria: [s..n.], p. 201-209. ISBN: 978-65-992356-0-3

Santos, A.B. dos; Silva, S.C. da; Zimmermann, F.J.P. (2003). Efeitos do manejo da irrigação na temperatura da água e no comportamento do arroz irrigado. In: CONGRESSO BRASILEIRO
DE ARROZ IRRIGADO, 3.; REUNIÃO DA CULTURA DE ARROZ IRRIGADO, 25.; Balneário Camburiú, SC. Anais. Itajaí: EPAGRI, 2003. p. 181-183.

Stone, L.F. (2005). Eficiência do Uso da Água na Cultura do Arroz Irrigado. Santo Antônio de Goiás: Embrapa Arroz e Feijão. 48 p. (Embrapa Arroz e Feijão. Documentos, 176).

Stone, L.F.; Moreira, J.A.A.; Silveira Filho, A. (1990). Manejo de água na cultura do arroz: consumo, ocorrência de plantas daninhas, absorção de nutrientes e características produtivas. Pesquisa Agropecuária Brasileira, Brasília, 25(3): 323-337.

Yadav, Y.; Kumar, V. Feeding the world while caring for the planet. (2018). DSRC Newsletter, $1: 3-4$.

Yang, J.; Zhou, Q.; Zhang, J. (2017). Moderate wetting and drying increases rice yield and reduces water use, grain arsenic level, and methane emission. The Crop Jornal, 5: 151158. 